\title{
Levantamento das manifestações patológicas nas habitações Minha Casa Minha Vida na cidade de Joinville ${ }^{1}$
}

\section{Identifying pathologies in low-income households of Joinville}

\author{
Garcia, Janine 1; Bettoni, Daniele Heemann2; Kalbusch, Andreza3; Henning, \\ Elisa4; Garcia, Jayne 5 \\ 1 UDESC, Rua Paulo Malschitzki 200, Brasil, e-mail: janinegarcia01@gmail.com \\ 2 UDESC, e-mail: daniheemann@ig.com.br \\ 3 UDESC, e-mail: andreza.kalbusch@udesc.br \\ 4 UDESC, e-mail: elisa.henning@udesc.br \\ 5 UDESC, e-mail: jaynegarcia00@gmail.com
}

\begin{abstract}
RESUMO
A construção civil apresentou relativo crescimento até 2009, contudo devido à mão de obra pouco qualificada e falta de controle rigoroso sobre todas as obras, surgiram diversos problemas em relação à qualidade e desempenho das edificações. Em meio a isso, a Caixa Econômica Federal criou o programa "De Olho na Qualidade" a fim de cadastrar as contestações dos usuários acerca das condições físicas de seu imóvel e enviar ao construtor para resolução do problema. Nesse sentido, percebeu-se a necessidade de realizar um estudo com o objetivo de levantar as patologias identificadas pelo programa nos empreendimentos habitacionais Minha Casa Minha Vida da cidade de Joinville, nos anos de 2015 e 2016. Inicialmente efetuou-se uma coleta dos dados proveniente de denúncias cadastradas no Sistema de Gestão e Controle Atender com Qualidade PMCMV - SISAQ, em que os dados foram distribuídos em planilhas e manipulados estatisticamente por meio de gráficos comparativos e tabelas. Constatou-se que as manifestações patológicas mais apontadas pelos clientes no município de Joinville foram decorrentes de infiltração (42,5\%), revestimento cerâmico $(38,7 \%)$ e fissura $(34,4 \%)$. Essas principais patologias foram selecionadas para análise dos vícios construtivos apontados pelo cliente, utilizando os laudos técnicos elaborados pela Caixa.
\end{abstract}

Palavras-chave: programa De Olho na Qualidade, manifestações patológicas, Joinville.

\begin{abstract}
The civil construction sector showed a growth until 2009, however due to the low skill labour and the lack of control over the constructions, several problems regarding the quality and the building performance have been verified. Therefore, "Caixa Econômica Federal" created a program called "De Olho na Qualidade", in order to register users' complaint about their houses physical conditions and send it to the builder to solve the problem. In this sense, the need to conduct a study with the goal of knowing the pathologies identified by the program
\end{abstract}

1 GARCIA, Janine; BETTONI, Daniele Heemann; KALBUSCH, Andreza; HENNING, Elisa; GARCIA, Jayne. Levantamento das manifestações patológicas nas habitações Minha Casa Minha Vida na cidade de Joinville. In: II SIMPÓSIO NACIONAL DE GESTÃO E ENGENHARIA URBANA: SINGEURB, 2019, São Paulo. Anais... Porto Alegre: ANTAC, 2019. 
in the housing units of the program "Minha Casa Minha Vida" in Joinville during 2015 and 2016 was identified. Firstly the data were collected from complaints registered in the "Sistema de Gestão e Controle Atender com Qualidade PMCMV - SISAQ", in which data were distributed statistically through comparative charts. It was observed that the most frequent pathological manifestations were infiltration (42.5\%), problems involving ceramic coating (38.7\%) and crack (34.4\%). These three main pathologies were selected for the analysis of the constructive defects pointed out by the customers.

Keywords: "De Olho na Qualidade" program, pathological manifestations, Joinville.

\section{INTRODUÇÃO}

O setor da construção civil apresentou relativo crescimento até o ano de 2009 (MACENA, 2010). Consequentemente, surgiram mais oportunidades de crédito imobiliário, o que aumentou a quantidade de financiamentos habitacionais, muitos deles por meio do Programa Minha Casa Minha Vida - PMCMV, criado em 2009 pelo Governo Federal.

A grande quantidade de lançamentos no mercado e a abertura de crédito ocasionaram um pico na produção imobiliária para o qual o setor não estava preparado. Diante disso, diversos projetos foram elaborados às pressas, os materiais construtivos tornaram-se mais caros e escassos, praticamente não havia equipamentos disponíveis para locação, além da falta de operários e engenheiros qualificados (ROCHA, 2012).

Por isso, após receber várias ocorrências sobre vícios construtivos e como forma de monitorar a qualidade das unidades habitacionais dentro do PMCMV, a Caixa Econômica Federal CEF criou em 2013 o programa "De Olho na Qualidade". O programa visa registrar as reclamações dos usuários sobre as condições físicas do seu imóvel e encaminhá-las aos construtores para que sejam tomadas as devidas providências (CEF, 2017).

Borges e Sabbatini (2008) afirmam que o desempenho de uma edificação depende de vários agentes para ser atingido, desde os que concebem o projeto até os responsáveis pela sua manutenção e operação, tais como: projetistas, fabricantes de materiais, construtores, incorporadores, administradores pós-obra e o usuário final.

Sendo assim, avaliar o desempenho e o nível de degradação das edificações bem como prever a sua evolução futura é essencial para estabelecer requisitos de reparação e reabilitação (RODRIGUES; TEIXEIRA; CARDOSO, 2011). Outro fator importante é que a avaliação pós-ocupação possibilita uma melhoria na qualidade das edificações futuras, visto que retroalimenta o ciclo de produção (concepção, projeto e execução) por meio da verificação do seu desempenho (ARAÚJO, 2004).

Dessa forma, o intuito do trabalho foi realizar um levantamento das manifestações patológicas identificadas pelo programa "De Olho na Qualidade" nos empreendimentos habitacionais Minha Casa Minha Vida da cidade de Joinville nos anos de 2015 e 2016.

\section{METODOLOGIA}

No desenvolvimento desta pesquisa, primeiramente foi realizada uma coleta dos dados provenientes de denúncias cadastradas no SISAQ, Sistema de Gestão e Controle Atender com Qualidade PMCMV da Caixa, relativas à cidade de Joinville entre os anos de 2015 e 2016. A Figura 1 ilustra a página inicial do SISAQ. Trata-se de um programa online de abrangência nacional que é utilizado pela CEF para controle das ocorrências registradas tais como: gestão condominial, sinistro e dano físico nos empreendimentos por ela financiados.

Em todas as demandas são cadastradas informações como categoria da demanda, nome do cliente, imóvel objeto da contestação, responsável pela obra e manifestação do cliente. Na manifestação do cliente o problema verificado é relatado, e por último, é apresentado o histórico de ações realizadas nesta demanda (tentativa de contato, resposta do demandado, ateste assinado, entre outros).

Os dados referentes às manifestações patológicas foram organizados em planilhas e divididos 
de acordo com a causa para posterior manipulação estatística, a qual incluiu a geração de gráficos comparativos. A segunda parte do estudo consistiu em selecionar as três manifestações patológicas mais incidentes e representativas da população para analisar o motivo da sua ocorrência. Para isso, foram utilizados como base os autores da área e código de práticas da CEF.

Figura 1 - Página inicial do SISAQ

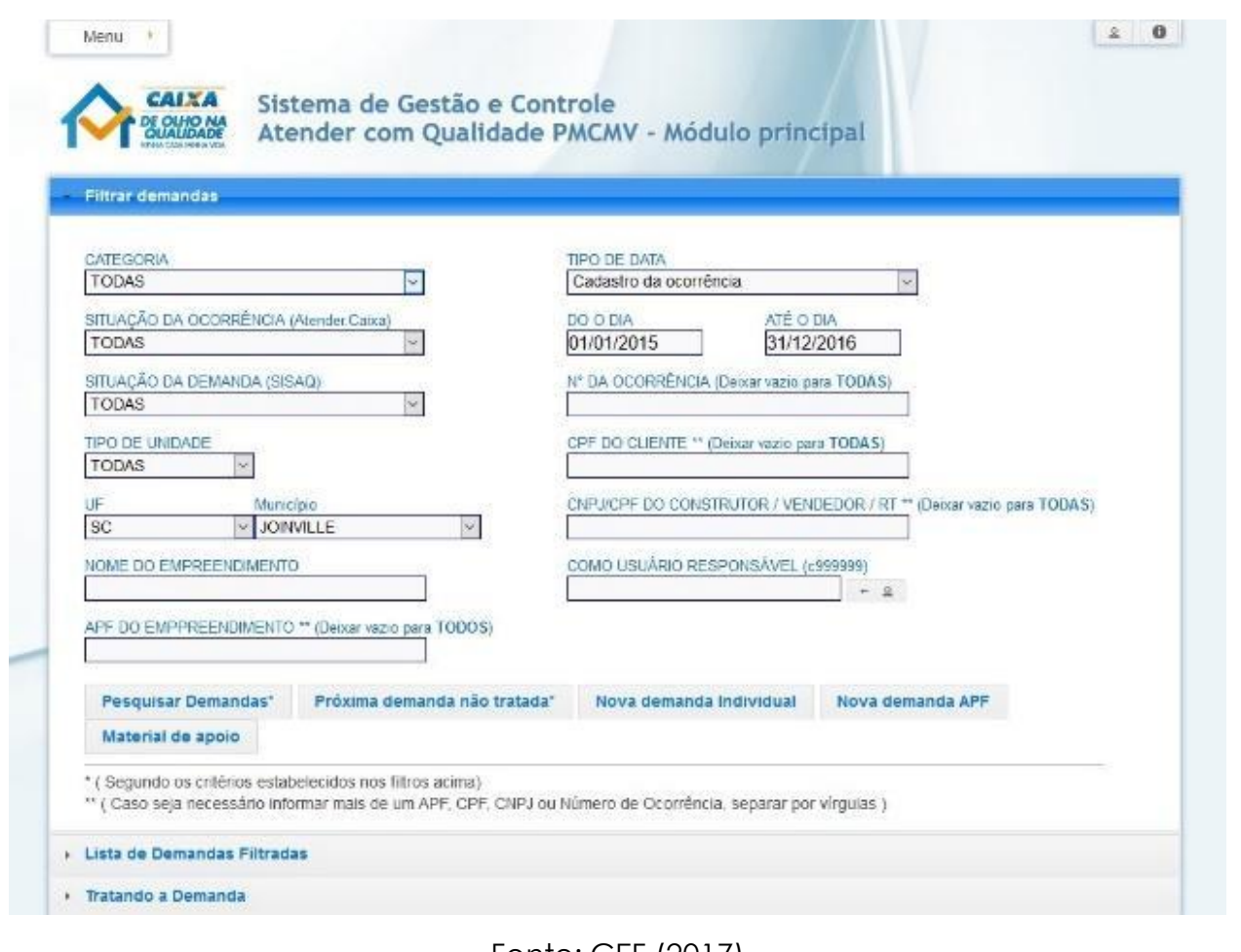

Fonte: CEF (2017)

\section{ANÁLISE DOS DADOS}

A seguir são apresentados os resultados e análise do levantamento de dados referentes a danos físicos do município de Joinville, cadastradas no sistema de monitoramento de ocorrências da CEF nos anos de 2015 e 2016. Considerando as premissas apresentadas, obteve-se um total de 242 ocorrências, das quais 124 foram relacionadas ao ano de 2015 e 118 , a 2016.

\subsection{Situação cadastral das ocorrências}

No SISAQ as ocorrências são categorizadas como: atrasada, pendente, com penalização, improcedente e concluída. Percebeu-se então um alto índice de ocorrências improcedentes, cujo percentual (23\%) alcançou aproximadamente um quarto do total de demandas recebidas.

Para prosseguir o estudo, foi necessário eliminar as ocorrências improcedentes, uma vez que elas poderiam interferir de maneira negativa e modificar o resultado final. Em virtude disso, nos resultados posteriores foram consideradas 186 ocorrências.

Nessa nova análise, $86 \%$ das demandas foram concluídas com a finalização dos reparos solicitados pelo cliente, $3 \%$ possuíam situação atrasada, $9 \%$ estavam com penalização e os $2 \%$ restantes estavam pendentes, como apresentado na Figura 2. As ocorrências penalizadas ou pendentes enquadraram-se nessas situações uma vez que os construtores não retornaram a comunicação feita pela CEF ou se negaram a prestar os serviços requeridos. 
Figura 2 - Percentual de ocorrências por situação da demanda desconsiderando a situação improcedente

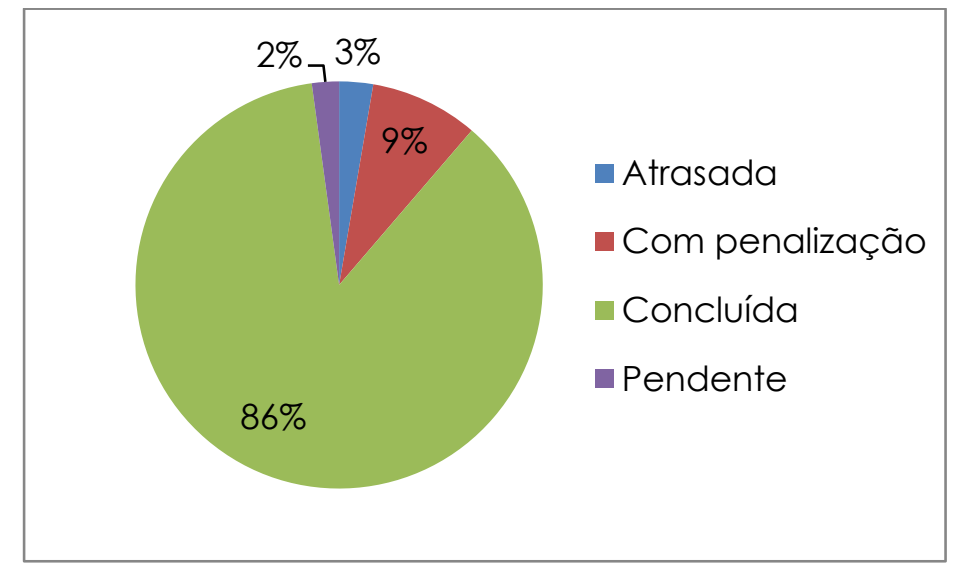

Fonte: Os autores

\subsection{Residenciais com maior número de ocorrências}

De acordo com a Figura 3, o residencial que mais recebeu ocorrências foi o residencial A, com 62 demandas. Foi um número bastante considerável de reclamações, pois representou $33 \%$ do total de ocorrências recebidas. O residencial $B$ recebeu 10 reclamações, seguido pelos residenciais $C$ e $D$, com 8 ocorrências cada e na sequência, o residencial $E$ com 7 demandas.

Figura 3 - Localização dos residenciais com maior número de ocorrências

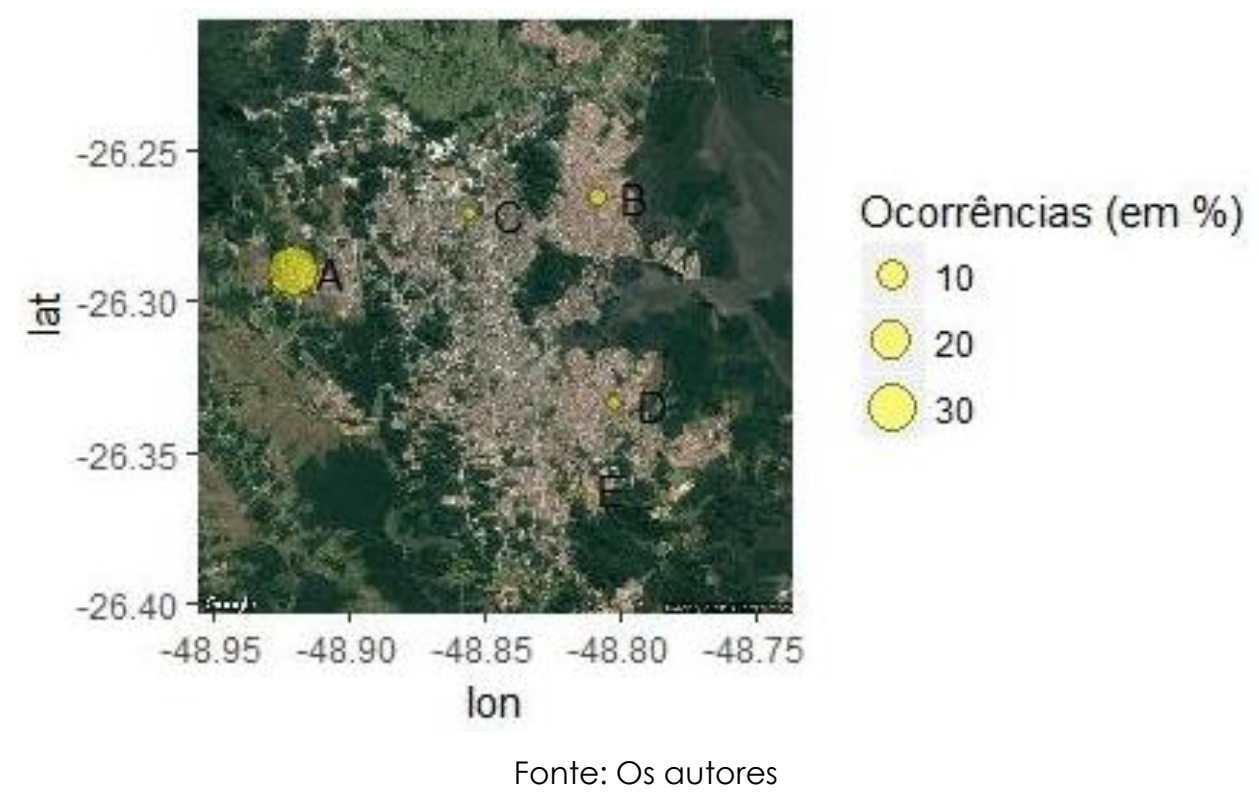

\subsection{Manifestações patológicas levantadas}

A categorização das manifestações patológicas foi efetuada com base na descrição do cliente, campo do SISAQ em que é relatado o problema verificado, e/ou no documento de execução dos serviços anexado ao histórico da demanda, no qual são discriminados os reparos efetuados pelo construtor.

Na Figura 4 pode-se perceber que as principais manifestações patológicas observadas nos empreendimentos MCMV em Joinville nos anos de 2015 e 2016, levantadas por meio das 186 ocorrências registradas, foram: infiltração $(42,5 \%)$, patologias no revestimento cerâmico $(38,7 \%)$, fissura $(34,4 \%)$, problemas na esquadria $(20,4 \%)$ e no sistema predial hidrossanitário 
$(15,6 \%)$. Também foram recebidas ocorrências relacionadas a vazamento $(14,5 \%)$ e problemas decorrentes da pintura $(14,0 \%)$, cobertura $(7,5 \%)$, churrasqueira $(5,4 \%)$, elétrica $(4,3 \%)$, pavimentação $(3,2 \%)$, recalque $(2,2 \%)$ e prumo $(1,1 \%)$.

Figura 4 - Manifestações patológicas nos empreendimentos MCMV em Joinville

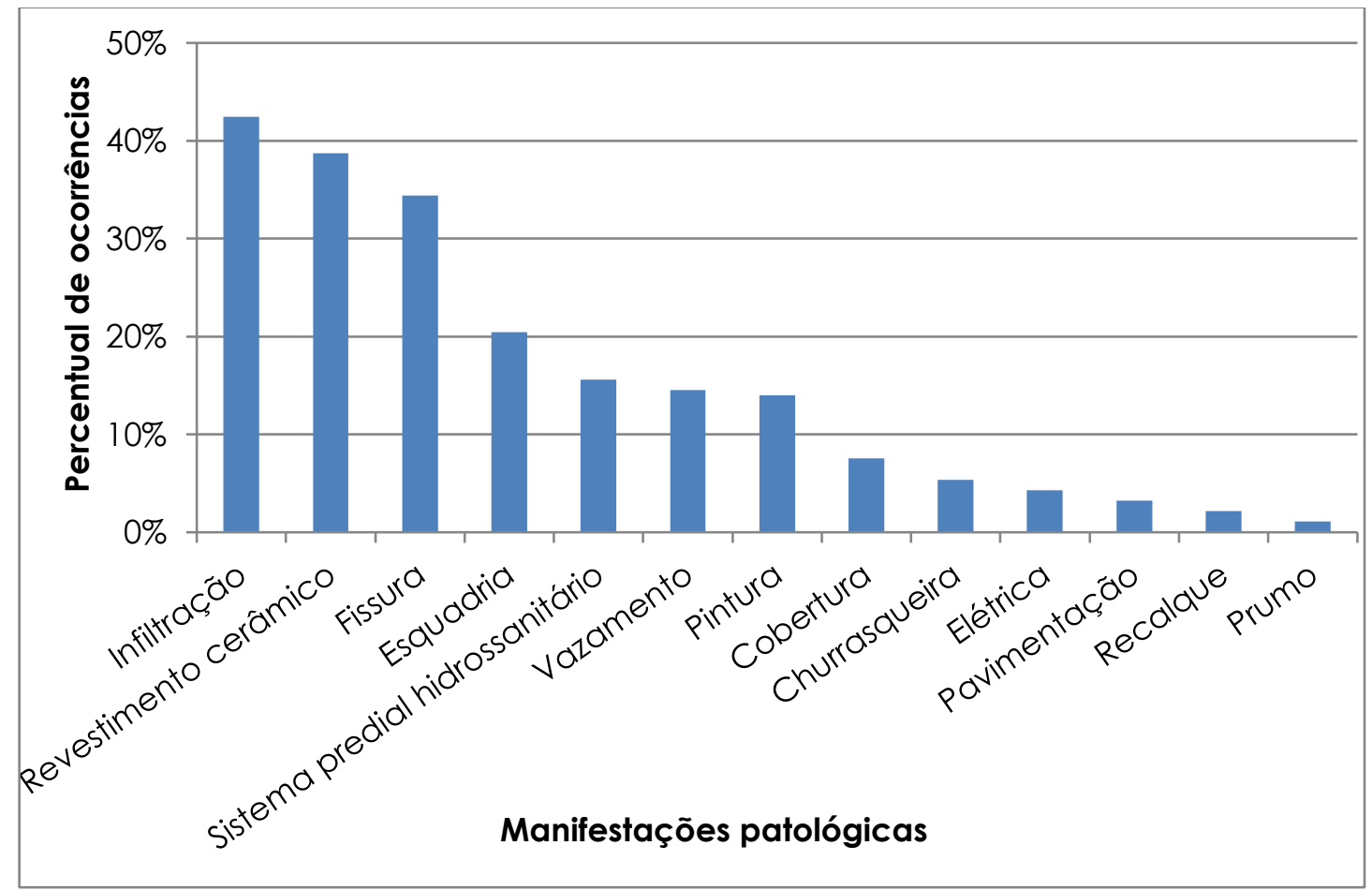

Fonte: Os autores

\section{ANÁLISE DAS MANIFESTAÇÕES PATOLÓGICAS}

A seguir são apresentados os resultados da análise das três manifestações patológicas mais incidentes, conforme o levantamento realizado. Grande parte das reclamações relacionadas à infiltração citou infiltração pela janela como uma manifestação patológica (Figura 5). Sendo assim, analisando os laudos referentes a essas ocorrências, verificou-se que a equipe técnica da CEF apontou como possível causa a falta de vedação das peças ou desempenho do material. Desta maneira, a falha estaria relacionada a erros na execução ou material de má qualidade, respectivamente.

Figura 5 - Danos à pintura e manchas de umidade devido à infiltração

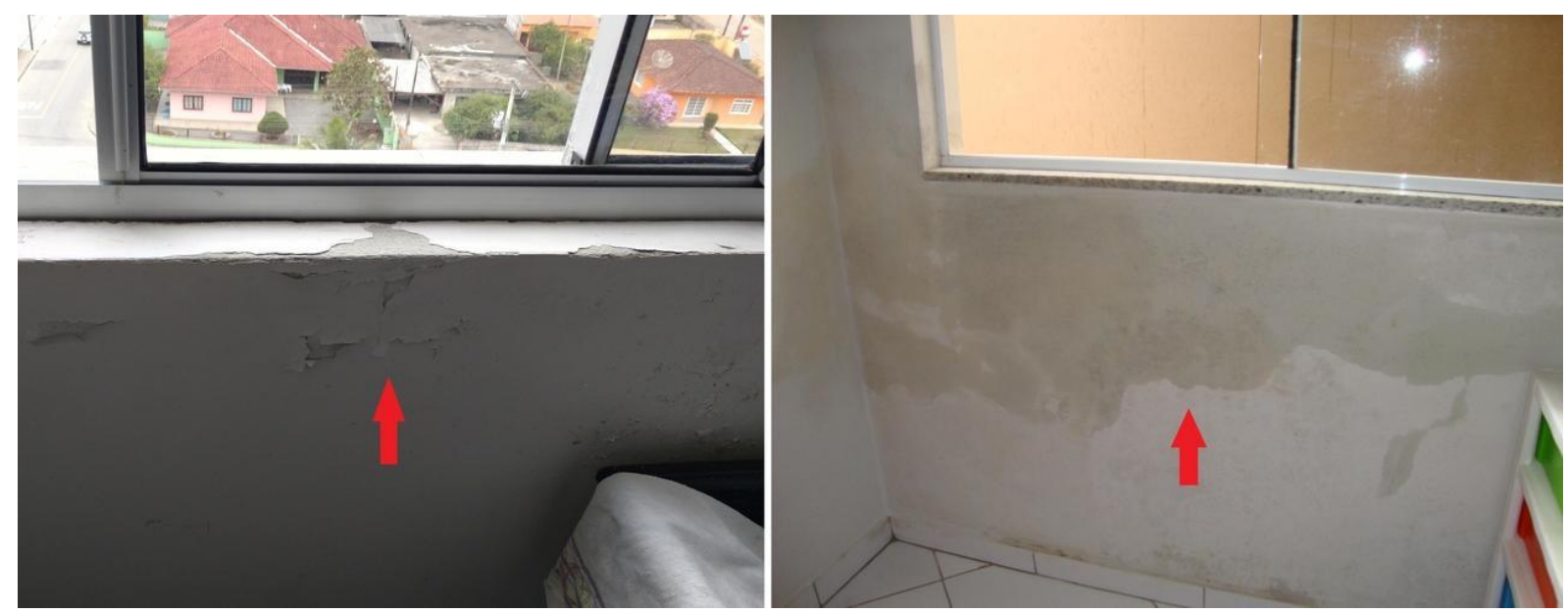

Fonte: CEF (2015) 
$\mathrm{Na}$ categoria revestimento cerâmico, tendo em vista a quantidade de ocorrências, foi escolhido para análise o desplacamento das peças (Figura 6), que pode ter como causa a falta de instrução da mão de obra no preparo da argamassa colante e utilização de técnicas e ferramentas inadequadas na colocação do revestimento. Outra possível causa está relacionada aos materiais empregados, como por exemplo, placas cerâmicas produzidas por via seca (CCB, 2010; SINDUSCON/SP, 2016).

Figura 6 - Desplacamento e estufamento de peças cerâmicas
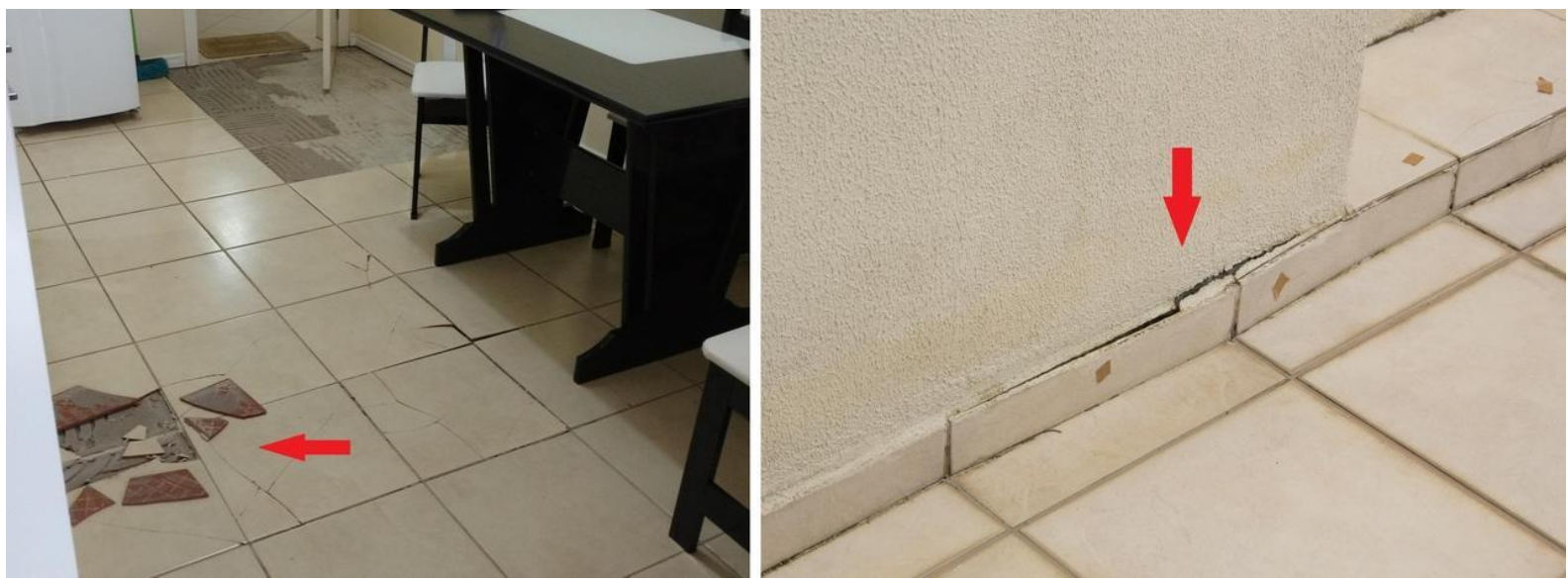

Fonte: CEF (2016)

Na categoria fissura, o estudo focou nas fissuras no revestimento argamassado devido ao número de demandas (Figura 7). A fissura por retração pode ter origem no revestimento pela perda de água para a base, nos materiais, devido à características como teor de finos e granulometria dos agregados, ou ainda nas técnicas de execução empregadas como grau de compactação e desempenamento (MEDEIROS; SABBATINI, 1994).

Figura 7 - Fissuras no revestimento argamassado

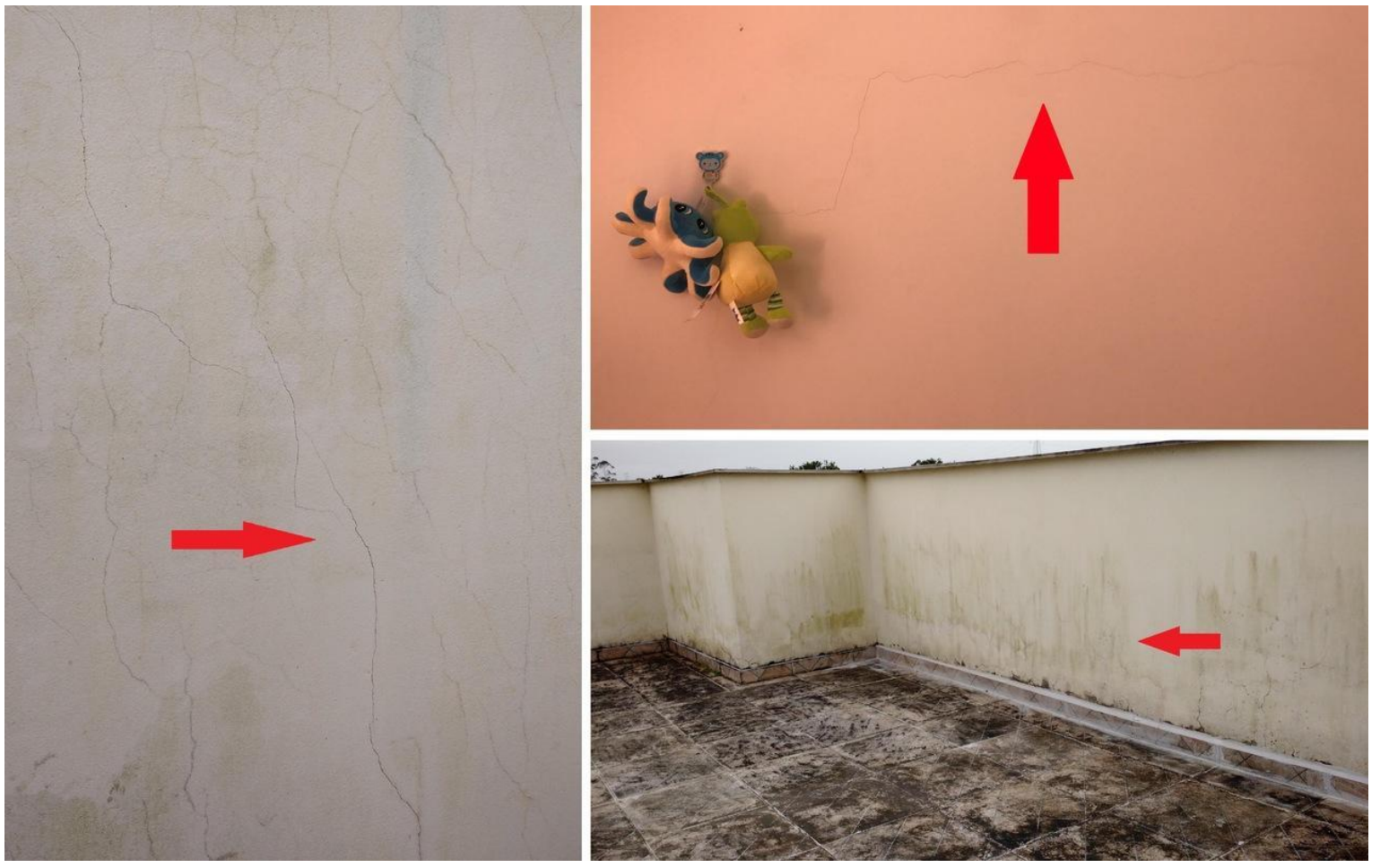

Fonte: CEF (2016) 


\section{CONCLUSÕES}

Ao final do estudo, concluiu-se que o percentual de ocorrências improcedentes foi alto (23\%). Por isso, é importante conscientizar os clientes para que eles procurem o programa De Olho na Qualidade somente se realmente houver algum dano físico em seu imóvel, que seja considerado vício construtivo e que ainda esteja dentro do prazo de garantia.

Por outro lado, desconsiderando as ocorrências improcedentes, das 186 restantes, $86 \%$ já estavam com a situação concluída, demonstrando que houve esforços, tanto por parte dos construtores quanto da equipe técnica da CEF para solucionar os vícios construtivos verificados nos imóveis MCMV em Joinville e assim, finalizar a demanda.

Conforme o levantamento realizado nessa pesquisa, as principais patologias nas habitações Minha Casa Minha Vida em Joinville nos anos de 2015 e 2016 foram decorrentes de infiltração $(42,5 \%)$, problemas no revestimento cerâmico $(38,7 \%)$ e fissura $(34,4 \%)$.

Portanto, é imprescindível a adoção de determinadas práticas para evitar o surgimento desses problemas como elaboração de projetos mais completos e com especificações detalhadas. Além disso, deve-se escolher adequadamente os materiais e produtos de acordo com a região de utilização e de preferência certificados pelos órgãos competentes; investir na qualificação da mão de obra e melhorar o controle de qualidade durante a execução da obra. Dessa forma, o programa atenderá o objetivo de diminuir o déficit habitacional com a construção de habitações de qualidade para a população de baixa renda.

\section{REFERÊNCIAS}

ARAÚJO, L. S. M. Avaliação durante operação dos sistemas prediais hidráulicos e sanitários em edifícios escolares. 2004. 231 f. Dissertação (Mestrado em Engenharia Civil) Universidade Estadual de Campinas, Campinas, 2004.

BORGES, C. A. de M.; SABBATINI, F. H. O conceito de desempenho de edificações e a sua importância para o setor da construção civil no Brasil. Boletim Técnico da Escola Politécnica da USP, São Paulo: EPUSP, 2008. Disponível em: <http://www.fau.usp.br/cursos/pos/areas/ area_tecnologia/aut5828/bł515_desempenho_edificios_borges_sabbatani.pdf $>$. Acesso em: 08 abr. 2017.

CEF - CAIXA ECONÔMICA FEDERAL. Programa De Olho na Qualidade: Código de práticas CAIXA. 7. ed. [Brasília, DF], 2017.

CCB - CENTRO CERÂMICO DO BRASIL. Manual de assentamento de revestimentos

cerâmicos: pisos internos. 2010. Disponível em: <http://www.ccb.org.br/assentamento/ manual_pisint.pdf>. Acesso em: 23 set. 2017.

MACENA, P. Desempenho recente do setor da construção e perspectivas para os próximos anos. Concreto \& Construções, São Paulo, ano 38, n. 57, p. 37-39, jan./mar. 2010. Disponível em: <http://www.ibracon.org.br/publicacoes/revistas_ibracon/rev_construcao/pdf/Revista _Concreto_57.pdf>. Acesso em: 14 abr. 2017.

MEDEIROS, J. S.; SABBATINI, F. H. Estudos sobre a técnica executiva de revestimentos de argamassa sobre paredes de alvenaria. In: International Seminar on Structural Masonry for Developing Countries, 5., Florianópolis, 1994. Proceedings. Florianópolis, UFSC/University of Edinburgh/ANTAC, 1994. p. 594-607.

RODRIGUES, M. F. S.; TEIXEIRA, J. M. C.; CARDOSO, J. C. P. Buildings envelope anomalies: A visual survey methodology. Construction \& Building Materials, [S. I.], v. 25, n. 5, p. 2741-2750, maio 2011. 
ROCHA, A. P. Qualidade em risco. Construção mercado, [São Paulo], ano 65, n. 130, p. 30-35, maio 2012.

SINDUSCON/SP - SINDICATO DA INDÚSTRIA DA CONSTRUÇÃO CIVIL DE SÃO PAULO. Desplacamento cerâmico é problema setorial e requer mobilização da cadeia produtiva. Jul. 2016. Disponível em: <https://www.sindusconsp.com.br/ desplacamento-ceramico-eproblema-setorial-e-requer-mobilizacao-da-cadeia-produtiva/>. Acesso em: 25 set. 2017. 